\title{
Characterization of the Thyroid Microsomal Antigen, and Its Relationship to Thyroid Peroxidase, Using Monoclonal Antibodies
}

\author{
Luc Portmann, Frank W. Fitch, W. Havran, Noboru Hamada, Wilbur A. Franklin, and Leslie J. DeGroot \\ Thyroid Study Unit, Department of Medicine, and Department of Pathology, The University of Chicago, Chicago, Illinois 60637
}

\section{Abstract}

MAb directed to the thyroid microsomal antigen have been developed. All bound to 101- and 107-kD bands in Western blot analysis using thyroid microsomal fraction as antigen. The MAb also bound to microsomal proteins immunoprecipitated by serum from patients having a high titer of anti-microsomal antibody but no antibodies to thyroglobulin or thyrotropinstimulating hormone receptor. The pattern of binding was related to the amount of reducing agent. The 101- and 107-kD bands were increased by addition of dithiothreitol whereas, in its absence, numerous bands of higher molecular weight were present, suggesting a multimeric protein structure. Despite the inability to immunoprecipitate thyroid peroxidase (TPO) enzymatic activity, the MAb bound intensively in Western blot to denatured purified hog TPO and to denatured immunopurified human TPO. Trypsin digestion of the 101-107-kD antigen produced a doublet of 84-88 $\mathbf{~} D$ that was still immunoreactive with MAb. One of five polyclonal sera tested (with a microsomal antibody titer $>1 / 20,480$ measured by the tanned red cell hemagglutination technique) also recognized the 84-88-kD trypsin fragments. Addition of $\mathrm{V8}$ protease led to a disappearance of the 107-kD protein, but not the 101-kD protein, proving that this antigen is formed by two different polypeptides. The MAb bound strongly to thyroid epithelium, whereas binding to papillary carcinoma was absent or low and moderate for follicular and Hurthle cell carcinoma.

This study indicates that the thyroid microsomal antigen and TPO are identical and are constituted of two different polypeptides. On SDS-PAGE the antigen appears as two contiguous bands which share common epitopes but are not identical, as proven by their size and difference in susceptibility to proteolytic digestion. The immunoreactivity of the molecule is highly dependent on a trypsin-sensitive site, which appears important in the recognition of the antigen by polyclonal sera and may have biological importance. The expression of microsomal antigenicity is variable among various thyroid carcinomas.

\section{Introduction}

Antibodies against the human thyroid microsomal antigen (M antigen) are frequently present in autoimmune thyroid disease

Address reprint requests to Dr. DeGroot, The University of Chicago, Thyroid Study Unit, Box 138, 5841 South Maryland Ave., Chicago, IL 60637.

Received for publication 11 March 1987 and in revised form 2 November 1987.

J. Clin. Invest.

(c) The American Society for Clinical Investigation, Inc.

$0021-9738 / 88 / 04 / 1217 / 08 \$ 2.00$

Volume 81, April 1988, 1217-1224
(AITD) $^{1}(1,2)$, and unlike other thyroid autoantibodies, fix complement, and thus may have a deleterious potential (3). This $M$ antigen has been described on the apical surface of human thyroid cells (4) and on a cloned rat cell line in vitro (5). The nature of this antigen has been difficult to establish as it is not readily soluble, and is often contaminated with thyroglobulin (TG) (6). We have previously identified the $M$ antigen by immunoprecipitation and Western blot analysis using sera of patients with $\operatorname{AITD}(7,8)$. In reduced and denatured conditions, this antigen appears in Western blots as a doublet of 101-107 kD using antibody of patients with AITD. Similar findings have been described using immunoprecipitation $(6$, 9). We speculated that there was a close intracellular relationship described between thyroid peroxidase (TPO) and M antigen, both of which are found in exocytotic vesicles, and we found antibodies in the sera of patients with AITD that could immunoprecipitate TPO enzymatic activity (10), suggesting their possible identity. However, the loose correlation between titers of antibodies against $M$ antigen by ELISA, and precipitation of TPO, suggested either that TPO and M antigen were different or that epitopes present in native TPO and in ELISA assays were not identical. Czarnocka et al. (11) have recently reported co-elution of TPO activity, and immunoreactivity measured by anti-microsomal antibodies from patients with AITD, from an immunoaffinity column prepared with MAb developed against thyroid membrane antigen. Other recent studies have reported MAb against crude thyroid microsomal proteins $(12,13)$ or purified peroxidase $(14)$, but none has taken as immunogen the specific microsomal antigen defined by polyclonal sera of patients with thyroid autoimmune disease. As SDS-PAGE allows precise localization of antigenic proteins identified previously by Western blot analysis, we developed MAb against the $107-\mathrm{kD}$ antigenic band to better characterize the microsomal antigen itself and its relationship to TPO.

\section{Methods}

Antigen preparation. Human thyroid microsomes were prepared, using snap-frozen tissue from patients with Graves' disease, by differential centrifugation at $800,10,000$, and $104,000 \mathrm{~g}$. The microsomal pellet was washed three times with PBS to remove soluble proteins (TG, hemoglobin, etc.) and stored at $-70^{\circ} \mathrm{C}$ until used. Microsomes were heated $3 \mathrm{~min}$ in a boiling water bath in $18 \mathrm{mM}$ Tris- $\mathrm{HCl}$ buffer, $\mathrm{pH}$ 6.8 , containing $2.5 \% \mathrm{SDS}, 2.25 \mathrm{M}$ urea, and 5\% mercaptoethanol, in addition to $10 \%$ glycerol and $0.002 \%$ bromophenol blue. The microsomal protein $(3 \mathrm{mg} / \mathrm{gel})$ was applied to SDS-PAGE based on the method of Victor et al. (15). The proteins were electrophoresed in a $6 \%$ gel. After running, small vertical strips were cut in the middle and in the edges, while the other parts were kept in PBS at $4^{\circ} \mathrm{C}$. The strips

1. Abbreviations used in this paper: AITD, autoimmune thyroid disease; DAB, 3,3' diaminobenzidine; MCHA, microsomal hemagglutination assay; TBS, $25 \mathrm{mM}$ Tris- $\mathrm{HCl}, 150 \mathrm{mM} \mathrm{NaCl}$; TG, thyroglobulin; TGHA, thyroglobulin hemagglutination assay; TPO, thyroid peroxidase; TSAb, thyroid-stimulating antibodies; TSH, thyrotropinstimulating hormone. 
were used to detect proteins by Coomassie Blue R 250 and to detect the antigenic band by Western blot as previously described (7). The antibodies were incubated $1 \mathrm{~h}$ and their binding was detected using a peroxidase-conjugated goat anti-human IgG (gamma chain-specific) (Cappel Laboratories, Cochranville, PA) in $25 \mathrm{mM}$ Tris- $\mathrm{HCl}, 150 \mathrm{mM}$ $\mathrm{NaCl}$ (TBS), $10 \%$ goat serum, and $0.05 \%$ Tween 20 . The peroxidase substrate was $0.05 \% 3,3^{\prime}$ diaminobenzidine (DAB) plus $0.3 \mathrm{mM} \mathrm{H}_{2} \mathrm{O}_{2}$ in TBS. This allowed localization of the $107-\mathrm{kD}$ band, which was then cut out and electroeluted in a dialysis bag in $40 \mathrm{mM}$ Tris plus $40 \mathrm{mM}$ boric acid at $\mathrm{pH} 8.6$, at $100 \mathrm{~V}$ for $3 \mathrm{~h}$ at $4^{\circ} \mathrm{C}$. Polarity was then reversed for $2 \mathrm{~min}$. The eluate was dialyzed against distilled water, lyophilized, and resuspended in a minimal volume of PBS.

Protein concentrations were determined by a modification of the method of Lowry et al. (16).

Immunization. 6-8-wk-old female BALB/c mice were injected intraperitoneally with $50 \mu \mathrm{g}$ of gel-purified thyroid microsomal 107-kD protein in complete Freund's adjuvant. Every 4 wk the mice were injected with the same amount of protein in PBS until the sera were shown to have antibodies binding to the $107-\mathrm{kD}$ protein by Western blot analysis, using a peroxidase-conjugated goat anti-mouse IgG plus IgM plus IgA. Animals with high serum titers received a booster injection of $20 \mu \mathrm{g}$ antigen in sterile saline, intravenously, $3 \mathrm{wk}$ after the last injection. $3 \mathrm{~d}$ later, the spleens were excised for fusion.

Cell fusion. Fusion was performed using polyethylene glycol (17) with some modifications (18). Splenocytes were fused with SP2/O myeloma cells (19).

Selection of hybridomas. After 10 to $21 \mathrm{~d}$ in culture, the clones were tested by dot-blot analysis and by Western blot analysis, since we found that sera from immunized mice bound in both conditions. In the dot-blot method, $5 \mu \mathrm{g}$ of briefly sonicated microsomal protein in 25 $\mathrm{mM}$ Tris- $\mathrm{HCl}$ plus $500 \mathrm{mM} \mathrm{NaCl}$ plus $\mathrm{pH} 7.4$ were coated on $0.45-\mu \mathrm{M}$ nitrocellulose paper using a microfiltration apparatus (Bio-Rad Laboratories, Richmond, CA) according to the instructions of the company. Supernatant of growing hybrids was allowed to filter by gravity for $\mathbf{4 5}$ min. Bound antibodies were visualized using DAB after incubation with a 1:500 dilution of peroxidase-conjugated IgG fraction goat antimouse IgG plus IgM plus IgA (Cappel Laboratories). Positive hybrids were expanded and further tested by Western blot analysis. Thereafter, the positive hybrids were cloned two times by limiting dilution in the supernatant from a 3-d-old culture containing $1 \times 10 / \mathrm{ml}$ irradiated $(1,200 \mathrm{rad})$ Lewis rat thymocytes. Clones were expanded in $25-\mathrm{cm}^{2}$ flasks or in vivo in the peritoneal cavities of tetramethylpentadecanetreated BALB/c female mice for the production of ascitic fluid. Monoclonal antibody was used from ascites fluid or after purification by MAPS-protein A kit (Bio-Rad Laboratories) and dialysis for $24 \mathrm{~h}$ at $4^{\circ} \mathrm{C}$ in $0.02 \mathrm{M}$ phosphate buffer, $\mathrm{pH}$ 7.4. IgG subclass was determined by the double immunodiffusion method of Ouchterlony using mouse isotype-specific rabbit antibodies (Miles Laboratories, Elkhart, IN).

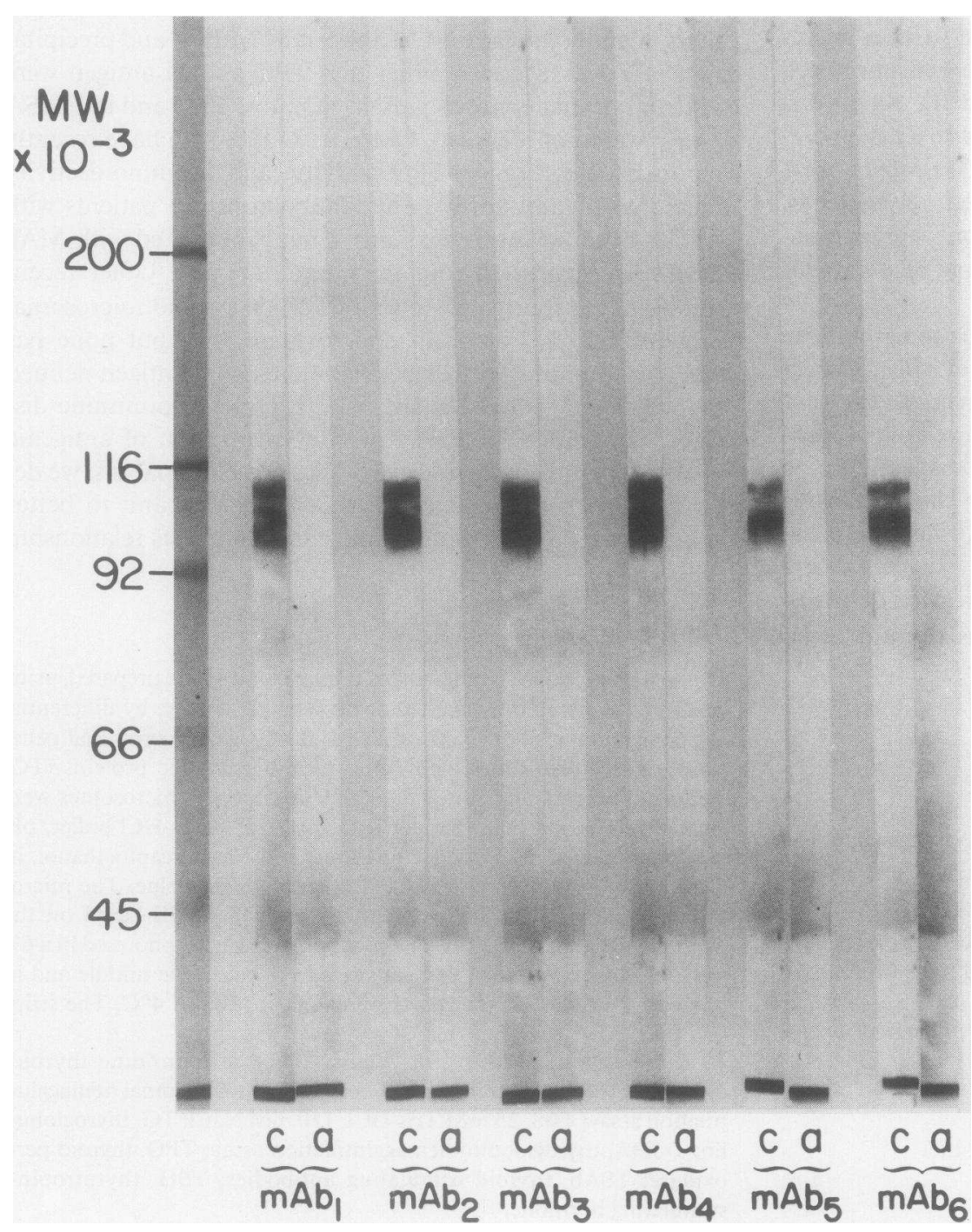

Figure 1. Binding of six MAb to thyroid microsomal proteins immunoprecipitated by serum of a patient with AITD. Microsomal fraction was solubilized overnight with $n$-octyl glycoside. $1.3 \mathrm{mg}$ of solubilized protein was stripped of IgG by incubating with Pansorbin. The supernatant was divided in two and added to $40 \mu \mathrm{l}$ of human sera ( $c$ and $a$ ). The sera were characterized as follows: $(c) 107$ $\mathbf{k D}+$, microsomal hemagglutination assay (MCHA+), TRAb-, Hashimoto's patient serum; and (a) $107 \mathrm{kD}-$, MCHA-, control serum. The immune complexes were precipitated with Pansorbin, washed five times in TBS $+0.5 \% \mathrm{NP}-40$, and eluted in $25 \mathrm{mM}$ Tris- $\mathrm{HCl}$, pH 6.8, containing 5\% SDS and 2mercaptoethanol before electrophoresis (6\% gel) and Western blot. A strip of nitrocellulose paper was then incubated with each MAb and bound antibodies were visualized using peroxidase-conjugated goat anti-mouse IgG immunoglobulins. MW, Molecular weight (for all figures). 


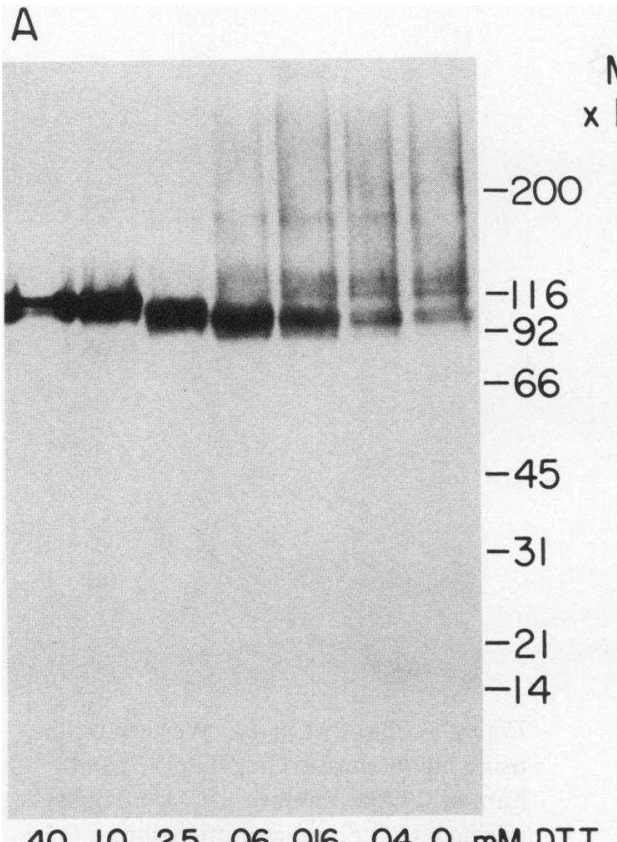

$\begin{array}{lllllllll}40 & 10 & 2.5 & .06 & .016 & .04 & 0 & \mathrm{mM} & \mathrm{DTT}\end{array}$

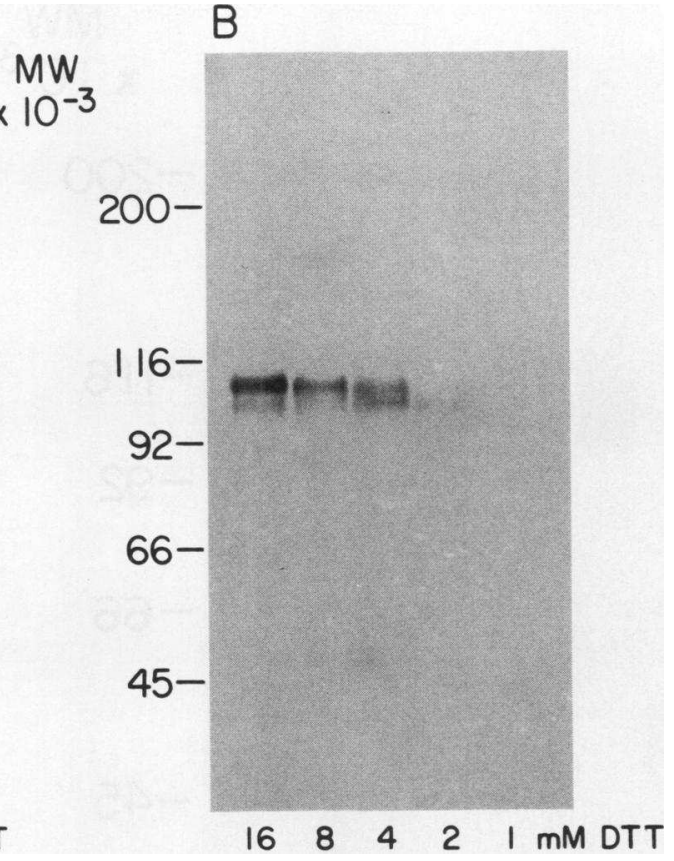

Figure 2. Effect of a reducing agent on the pattern of the immunoreactive bands in Western blots, as detected by anti-microsomal antigen MAb. (A) Western blot of microsomal proteins incubated with graded amounts of dithiothreitol in the sample treatment buffer (final concentration, 0-40 mM). Samples, each containing $100 \mu \mathrm{g}$ of proteins, were then applied to a 3.3-20\% linear polyacrylamide gradient gel. The nitrocellulose sheet was incubated with 1:1,000 dilution of ascitic fluid of $M A b_{1}$ and developed with peroxidase-linked second antibody. (B) As above, but $50 \mu \mathrm{g}$ protein was applied and MAb was used at $1: 2,500$ dilution.
Immunoprecipitation by polyclonal serum and Western blot analysis. The microsomal fraction was solubilized overnight in PBS with 40 $\mathrm{mM}$-octyl glycoside (Sigma Chemical Co., St. Louis, MO) at $4^{\circ} \mathrm{C}$. After a 60 -min centrifugation at $104,000 \mathrm{~g}, 700 \mu \mathrm{l}(1.2 \mathrm{mg})$ of the solubilized microsomes was added to $500 \mu \mathrm{l}$ of $10 \%$ Pansorbin (Calbiochem-Behring Corp., La Jolla, CA), which was previously washed in TBS with $0.5 \% \mathrm{NP}-40$ to remove IgG from the preparation of microsomes. Previous studies showed that this treatment removed IgG completely, as determined by immunoassay of residual IgG. After incubation for $60 \mathrm{~min}$, the material was centrifuged at $12,000 \mathrm{~g}$ for 5 min and $1,000 \mu \mathrm{l}$ of supernatant was collected and divided into two equal portions. $500 \mu \mathrm{l}$ was added to $40 \mu \mathrm{l}$ of serum of a patient (c) with high anti-microsomal antibody titer in the microsomal antigen tanned red cell agglutination test (MCHA > 1:24560) and no antibody to TG or thyrotropin-stimulating hormone (TSH) receptor. MCHA and thyroglobulin hemagglutination assay (TGHA) were measured by SeraTek microsomal antibody test and Sera-Tek thyroglobulin antibody test, respectively (Ames Div., Miles Laboratories). Thyroid-stimulating antibodies (TSAb) were measured using kits prepared by R.S.R. LTD, Cardiff, United Kingdom. The other portion was added to a control serum (a). The preparation was tumbled overnight at $4^{\circ} \mathrm{C}$ and washed five times with TBS $0.5 \%$ NP-40. The immune complexes were eluted in sample treatment buffer and boiled $3 \mathrm{~min}$ before a 5-min centrifugation at $10,000 \mathrm{~g}$ at room temperature. The supernatant was then electrophoresed and electroblotted. After blocking with 5\% dried skim milk the nitrocellulose sheet was cut into 5-mm wide strips and incubated with MAb (1:800 dilution of ascites fluid) against the 107-kD band. Bound antibodies were revealed by peroxidase-conjugated antibodies.

Immunoprecipitation of TPO by MAb. TPO was solubilized and used as previously described (10). A dose-response relationship was first determined using normal mouse serum and ascites fluid developed by a nonspecific hybridoma. At 1:8 dilution of ascites or serum no nonspecific effect was observed. The MAb were then incubated overnight with the TPO preparation at $4^{\circ} \mathrm{C}$ before the addition of Pansorbin, which had previously been incubated with rabbit antimouse IgG and washed in TBS $0.5 \%$ NP-40. After a 5-min centrifugation, the supernatant was collected and assayed for peroxidase activity using the guaiacol method.

Immunohistochemical studies. Snap-frozen, 4- $\mu \mathrm{M}$ cryostat sections of human tissues were incubated with MAb. The tissues studied included normal thyroid, colloid nodules, Graves' disease thyroid tissue, follicular, papillary, and Hurthle cell carcinomas, parathyroid, pancreas, stomach, skin, skeletal muscle, lymph node, spleen, and tonsil. Six MAb against the $107-\mathrm{kD}$ band (1:2,500 dilution of ascites), one anti-TG MAb (1:100 dilution of culture supernatant), and KB-90 (1:10 dilution of stock) (Dako Corp., Santa Barbara, CA), which is a MAb directed against an epitope present in mononuclear phagocytes, were used in these studies. The sections were processed as described by Cordel et al. (20). In brief, the sections were incubated successively with MAb diluted in TBS plus $1 \%$ BSA plus $0.03 \%$ sodium azide for 30 $\mathrm{min}$, rabbit anti-mouse $\mathrm{IgG}$ for $60 \mathrm{~min}$, and a suspension of soluble immune complexes containing alkaline phosphatase and mouse MAb to alkaline phosphatase (30 min), both from Dako Corp. Every step was separated by a 5-min wash in TBS. The substrate was prepared as follows: $2 \mathrm{mg}$ of naphtol AS-MX was dissolved in $0.2 \mathrm{ml}$ of dimethylformamide in a glass tube, and then $9.8 \mathrm{ml}$ of $0.1 \mathrm{M}$ Tris- $\mathrm{HCl}, \mathrm{pH} 8.2$, was added. Immediately before use, $6 \mathrm{mg}$ of Fast Red TR was added

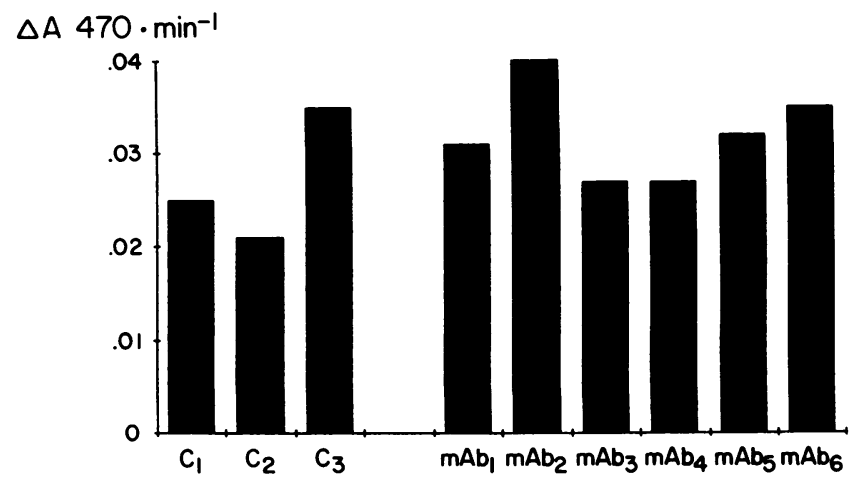

Figure 3. Double immunoprecipitation of TPO enzymatic activity by the six MAb anti-microsomal antigen. $M A b_{1-6}$ represent peroxidase activity in the supernatant after incubation of the six MAb (1:8 dilution of ascites) with solubilized TPO and addition of Pansorbin rabbit anti-mouse IgG. $C_{1}$, MAb and Pansorbin are omitted. $C_{2}$, MAb are omitted. $C_{3}, 1: 8$ dilution of ascites fluid (produced by nonspecific hybridoma). Peroxidase activity was measured by the guaiacol method. 


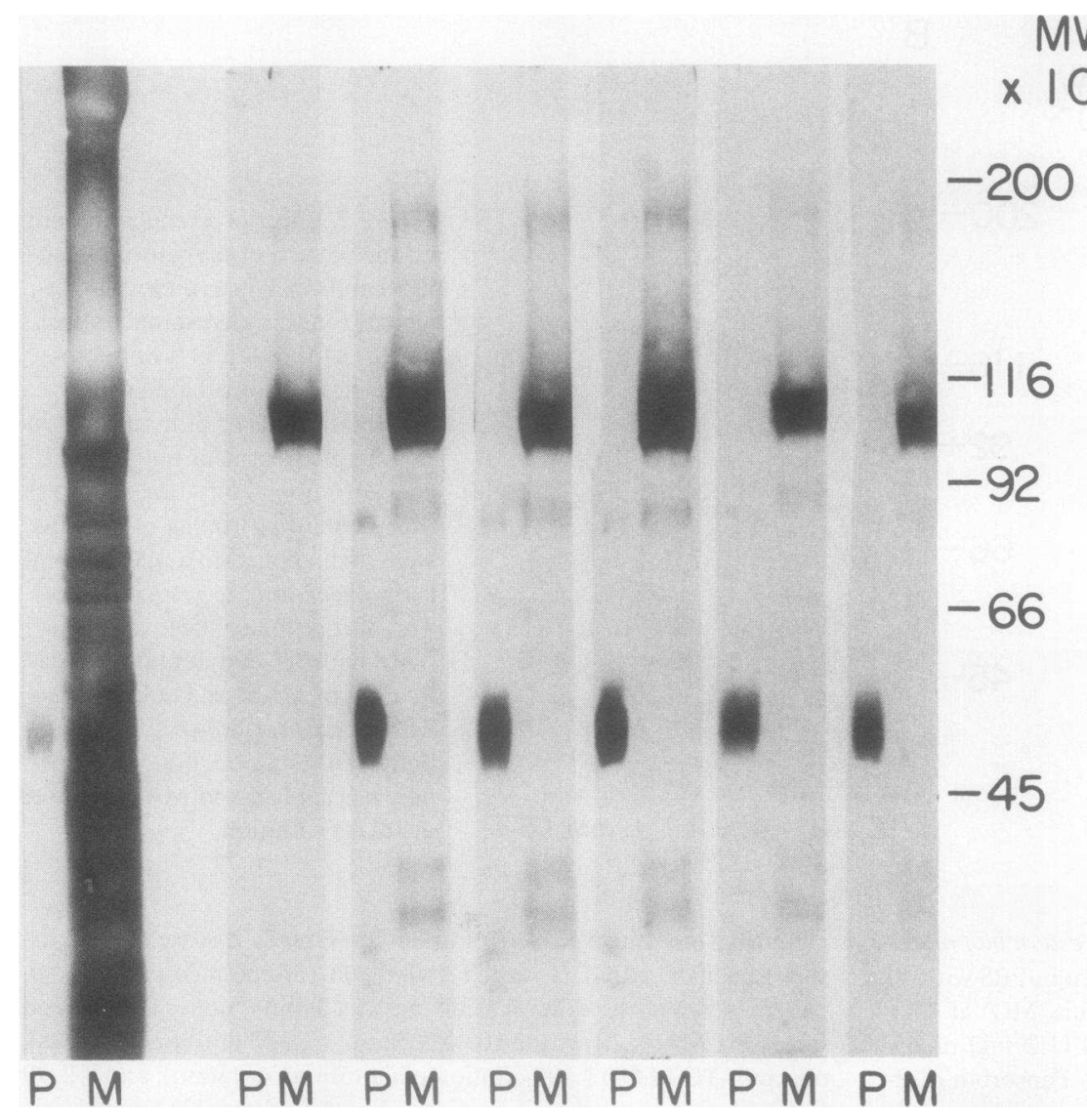

Figure 4. SDS-PAGE and Western blot using highly purified hog TPO $(P)$ and human thyroid microsomes $(M)$. Highly purified TPO $(2 \mu \mathrm{g})$ and microsomes (45 $\mu \mathrm{g})$ were run in denaturing and reducing conditions in each lane of a $6 \%$ gel. Part of the gel was used for silver staining, the other for immunoblot, and was done according to previously described methods. Each strip was incubated with 1:1,500 dilution of ascites fluid containing each of the six MAb. and applied on the slide through a $0.45 \mu \mathrm{m}$ filter. The sections were counterstained with hematoxylin and mounted.

Proteolysis of the microsomal fraction. The two enzymes used were trypsin, type III-S, from bovine pancreas (Sigma Chemical Co.) and protease, and Staphylococcus aureus V8 (Miles Scientific Div., Miles Laboratories). Solubilized microsomal fraction was incubated with 4 $\mu \mathrm{g}$ of trypsin/100 $\mu \mathrm{g}$ solubilized protein in a shaking waterbath for 30 min. The reaction was stopped by adding a fivefold excess of chromatographically purified soybean trypsin inhibitor (Sigma Chemical Co.). A control sample was treated similarly, but trypsin inhibitor was added before addition of trypsin. After electrophoresis the proteins were stained by Coomassie Blue and electroblotted before incubation with human polyclonal and MAb. In addition to control human sera, five MCHA (+) and TGHA ( - ) sera were used. Two of these were from patients with untreated Graves' disease, and three were from patients with Hashimoto's disease on thyroxine therapy.

Protease, $S$. aureus V8 was added in graded amounts $(25,50$, and $100 \mu \mathrm{g})$ to $400 \mu \mathrm{g}$ of solubilized microsomal preparation and incubated in a shaking waterbath at $37^{\circ} \mathrm{C}$ for $30 \mathrm{~min}$. The control sample did not include the enzyme. The samples were then quickly treated with sample treatment buffer and boiled. $80 \mu \mathrm{g}$ of microsomal protein was applied per lane to PAGE. The nitrocellulose sheets were exposed to diluted antibodies, and bound antibody was visualized either by using ${ }^{125}$ I-protein A (7) followed by autoradiography when using polyclonal serum, or by using peroxidase-labeled second antibody when MAb were applied.

\section{Results}

$M A b$ recognize the thyroid microsomal antigen. Six MAb reacting with the 107-kD band of thyroid microsomal fraction were identified. The MAb were obtained from two separate fusions using different mice, and thus represent two or more separate clones. These antibodies were of the IgG1 isotype. All bound solely to $101-$ and $107-\mathrm{kD}$ bands when microsomal proteins were electrophoresed in denaturing and reducing

Table I. Tissue Binding of MAb against the Microsomal Antigen (TPO)

\begin{tabular}{|c|c|c|c|}
\hline & $\begin{array}{c}\text { MAb* anti- } \\
107 \mathrm{kD}\end{array}$ & $\mathrm{MAb}^{\ddagger}$ anti-TG & $\begin{array}{l}\text { MAb }^{8} \\
\text { control }\end{array}$ \\
\hline \multicolumn{4}{|l|}{ Thyroid tissues } \\
\hline Graves' & +++ & ++++ & - \\
\hline Colloid nodules & $\begin{array}{l}+++ \\
\text { (Epithelium } \\
\text { only) }\end{array}$ & $\begin{array}{l}++++ \\
\text { (Epithelium } \\
\text { and colloid) }\end{array}$ & - \\
\hline Carcinoma: Papillary & $+1-$ & +++ & - \\
\hline Follicular & +++ & +++ & - \\
\hline Hurthle cells & ++ & +++ & - \\
\hline $\begin{array}{l}\text { Control tissues } \\
\text { Parathyroid, pancreas, } \\
\text { stomach, skin, muscle, } \\
\text { thymus }\end{array}$ & - & - & - \\
\hline $\begin{array}{l}\text { Spleen, lymph node, tonsils, } \\
\text { mononuclear phagocytes }\end{array}$ & - & - & ++++ \\
\hline
\end{tabular}

* Represents the pattern of binding of the six MAb used at 1:3,000 dilution of ascites fluid. +, Present; - absent.

${ }^{\ddagger}$ Represents the binding of one MAb used at 1:10 dilution of culture medium.

8 Represents a control MAb with no reactivity for microsomal antigen. This antibody, KB-90 (Dako Corp.), is directed to mononuclear phagocytes, and was used at 1:1 dilution. 
conditions (data not shown). To prove that the MAb were directed to the same protein as human anti-microsomal antibodies, the immunoprecipitate formed by a well-defined human serum (MCHA+, TGHA-, TRAb-) was electrophoresed and electroblotted onto nitrocellulose. Fig. 1 shows the binding of the six MAb to the immunoprecipitate of this serum, revealing the same $101-$ and $107-\mathrm{kD}$ bands previously described. Control serum did not immunoprecipitate any immunoreactive protein. The same negativity was observed when using a fourfold increase in control serum, confirming the specificity of the immunoprecipitation by AITD serum.

A change in the binding of MAb was observed depending on the presence of reducing agent (21). In nonreducing conditions, as shown in Fig. $2 A$, MAb bound to several bands of higher molecular weight than the $101-107-\mathrm{kD}$ bands. With increasing amounts of dithiothreitol, MAb bound mainly to 101- 107-kD bands. When used at higher dilution, the MAb bound only to the fully reduced antigen as shown in Fig. $2 B$.
$M A b$ to microsomal antigen bind to purified human and porcine TPO. MAb did not precipitate peroxidase activity. Fig. 3 shows the results of a typical experiment. The experiment was repeated four times. Increasing the amount of MAb and/ or second antibody, or decreasing the amount of TPO, had no specific effect. Purified MAb did not provide positive data. This is probably because our MAbs bind to a denatured antigen, and much less to a fully native antigen. As shown in Fig. 4 , five of the MAb bound on Western blot to highly purified hog TPO (22) (gift of Dr. A. Taurog, Southwestern University, Dallas, TX), which appeared as a single band by silver staining with a molecular weight of $54 \mathrm{kD}$. This low molecular weight is probably related to solubilization, trypsinization, and purification of this hog TPO. This contrasts with the binding to human thyroid microsomal fraction antigens, which have much higher molecular weights. In addition, MAb bound to several other bands, one of higher molecular weight (possibly a native form of TPO), and several of lower molecular weight
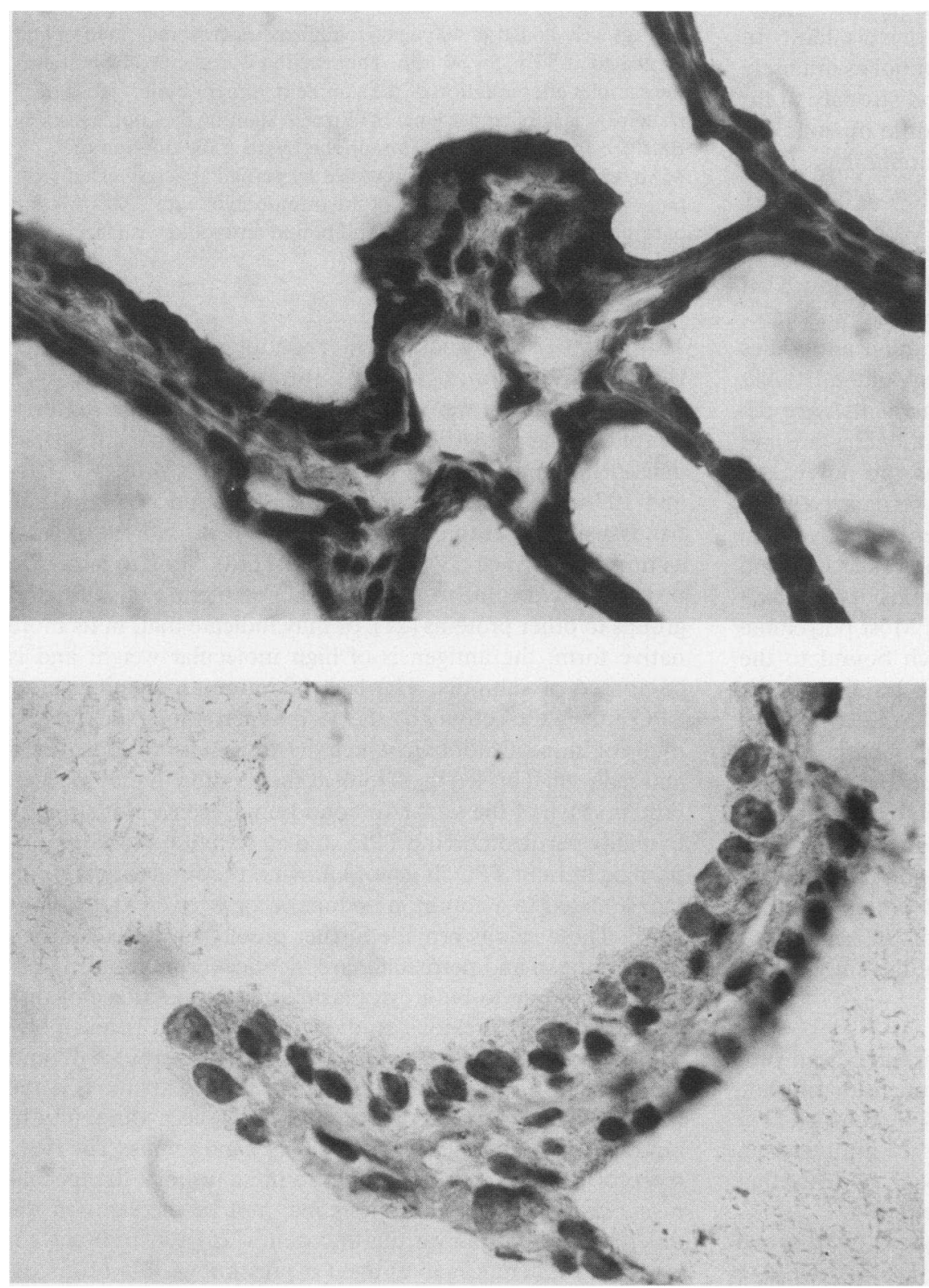

Figure 5. Staining of thyroid colloid nodule with an MAb against microsomal antigen (top) used at 1:3,000 dilution, and an MAb against mononuclear phagocytes (bottom) used at 1:10 dilution using the APAAP procedure (see Methods). 
(possibly proteolysis of antigen). When using a pig thyroid microsomal fraction, prepared conventionally, MAb bound to 101-107-kD bands (data not shown). The MAb all bound to immunopurified human TPO (gift Dr. P. Carayon), recognizing contiguous bands of 95 and $105 \mathrm{kD}$ (data not shown). These immunoreactive bands are similar to those Czarnocka et al. (11) have detected by Coomassie Blue staining after eluting bound microsomal proteins from Sepharose 4B coupled with anti-TPO MAb.

Immunohistochemical studies. All MAb directed against the 101-107-kD bands bound specifically to thyroid tissue (Table I and Fig. 5), and all of those MAb had the same pattern of binding. There was no staining of colloid, in contrast to the effect using antibody against TG. At 1:5,000 dilution of ascites fluid, the staining was predominantly at the apical border of the cells, using Graves' disease thyroid and colloid nodule tissues. At lower dilution the thyroid cell cytoplasm appeared homogeneously positive. Binding to thyroid carcinoma was variable. In follicular carcinomas MAb directed against the $107-\mathrm{kD}$ protein bound strongly, to about the same extent as to colloid nodules. In the papillary carcinomas tested the expression of the microsomal antigen was absent or very faint. In Hurthle cell carcinoma these MAb bound, but not as intensely as to follicular carcinoma. MAb to TG bound strongly to tumorous and nontumorous thyroid tissue, and no obvious difference was observed between the different carcinomas.

Identification of epitopes by partial antigen proteolysis. We studied the ability of the MAb and sera from patients with AITD to bind to peptide fragments of the microsomal antigen after digestion with enzymes. Incubation with V8 protease led to a loss of the 107-kD band as seen by Coomassie Blue staining and binding of both monoclonal and human antibodies (Fig. 6). A moderate decrease of the antigenicity of the 101-kD band was observed. Additional antigenic fragments were detected by the MAb, implying that these antibodies are not directed against the same antigenic sites as the polyvalent AITD antibodies studied, or that the epitopes recognized are of minor importance in most human polyvalent antiserum. In contrast, digestion by trypsin led to a total loss of the 101- and 107-kD bands, and created two contiguous bands of 84 and 88 kD, which were detected by MAb (Fig. $7 A$ ). Most polyclonal sera, including serum from patient $\mathrm{c}$, which bound to the 101-107-kD proteins (Fig. $6 \mathrm{~A}$ ), showed no binding to the trypsinized antigen. One sera bound strongly to the new form of antigen (Fig. $7 E$ ). There was thus a major difference in the pattern of recognition of antigen by different human antibodies. Some serum, despite strong binding to microsomal antigen by hemagglutination test, ELISA, and immunoprecipitation, did not bind to the denatured and reduced microsomal antigen. Other sera, while binding to the $107-\mathrm{kD}$ protein, did not bind to the trypsinized protein. Only one of the sera tested bound to the same extent to the two forms of the antigen.

\section{Discussion}

Six MAb to the human microsomal antigen have been produced and characterized with respect to affinities and binding to various conditions of this antigen, and by binding to TPO and human tissues. These MAb, derived by immunization with a well-defined microsomal antigen, provide evidence that the microsomal antigen and the TPO are identical.

All MAb showed specific binding to thyroid microsomal proteins; no crossreactivity was identified (23). They bound to

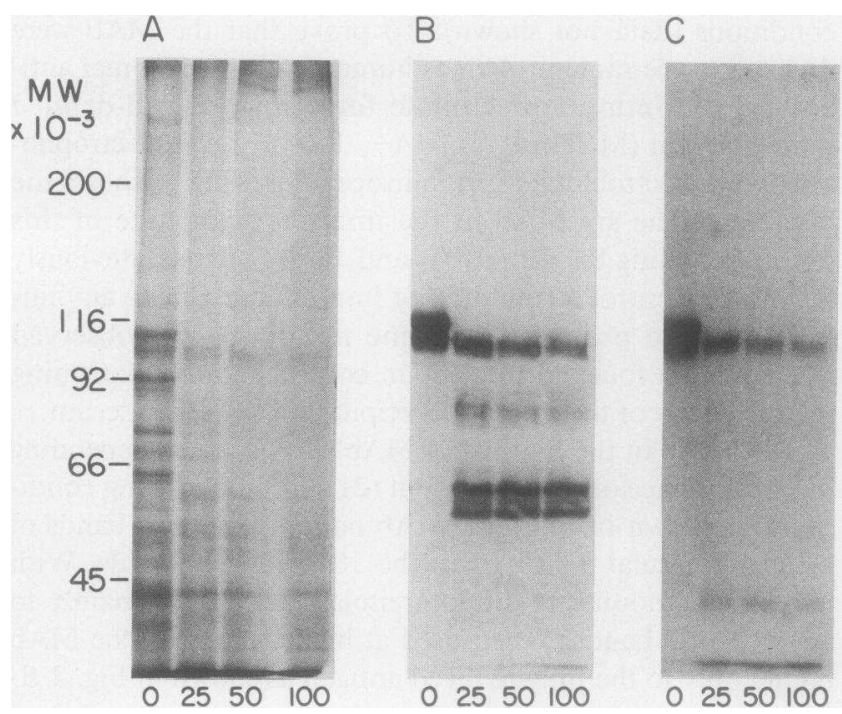

Figure 6. Effect of protease, $S$. aureus V8 on immunoreactivity of the microsomal antigen. Graded amounts of protease $(25,50$, and $100 \mu \mathrm{g}$ ) were added to $400 \mu \mathrm{g}$ of solubilized microsomal fraction and incubated at $37^{\circ} \mathrm{C}$ for $30 \mathrm{~min}$. The reaction was stopped by boiling the samples after addition of the sample treatment buffer. $80 \mu \mathrm{g}$ of proteins was applied per lane. $(A)$ Protein staining by Coomassie Blue. $(B)$ Incubation of the immunoblot with 1:800 dilution of $M A b_{1}$ and bound antibodies revealed by peroxidase-conjugated second antibody. $(C)$ Incubation of the immunoblot with 1:400 dilution of serum c (described in Fig. 1) and bound antibodies visualized by ${ }^{125}$ I protein $\mathrm{A}$.

101- and 107-kD bands when crude microsomal fraction or thyroid microsomal proteins immunoprecipitated by a MCHA (+) serum were run on SDS-PAGE. The characteristics of binding of MAb suggest that the microsomal antigen, in denaturing and reducing conditions, consists solely of 101and $107-\mathrm{kD}$ bands (8). We consistently found two antigenic bands, using either microsomal fraction (with/without trypsin) as immunopurified TPO. The pattern of binding to large-size proteins may be due to a nonspecific interaction of sulfhydryl groups to other proteins (21), or may indicate that, in its more native form, the antigen is of high molecular weight and is composed of subunits. The lack of immunoprecipitation of TPO enzymatic activity by the MAb is certainly related to the mode of immunization, in which the antigen is fully denatured and reduced. This led us to look at the binding to that purified protein. Five of the six MAb bound on Western blot strongly to highly purified porcine TPO, and all six bound to immunopurified human TPO. It is not known if the similarity of binding is related to a common epitope recognized by the various $\mathrm{MAb}$. These results provide further proof that thyroid microsomal antigen and peroxidase are identical proteins $(11,14)$.

The binding to both cytoplasm and apical surface of thyrocytes confirm previous studies using MAb (13) and polyclonal antibodies (24), implying that the "microsomal" and "microvillar" antigen are similar. Unlike MAb to TG, the $\mathrm{MAb}$ against the microsomal antigen showed a variability in binding to various histologic types of carcinomas. The TSH receptor is not always functional in these tumors; the mechanisms leading to carcinogenesis may not be the same in the different cancers; and various oncogenes (25) may be involved, leading to differences in antigen expression. A loss of micro- 
B
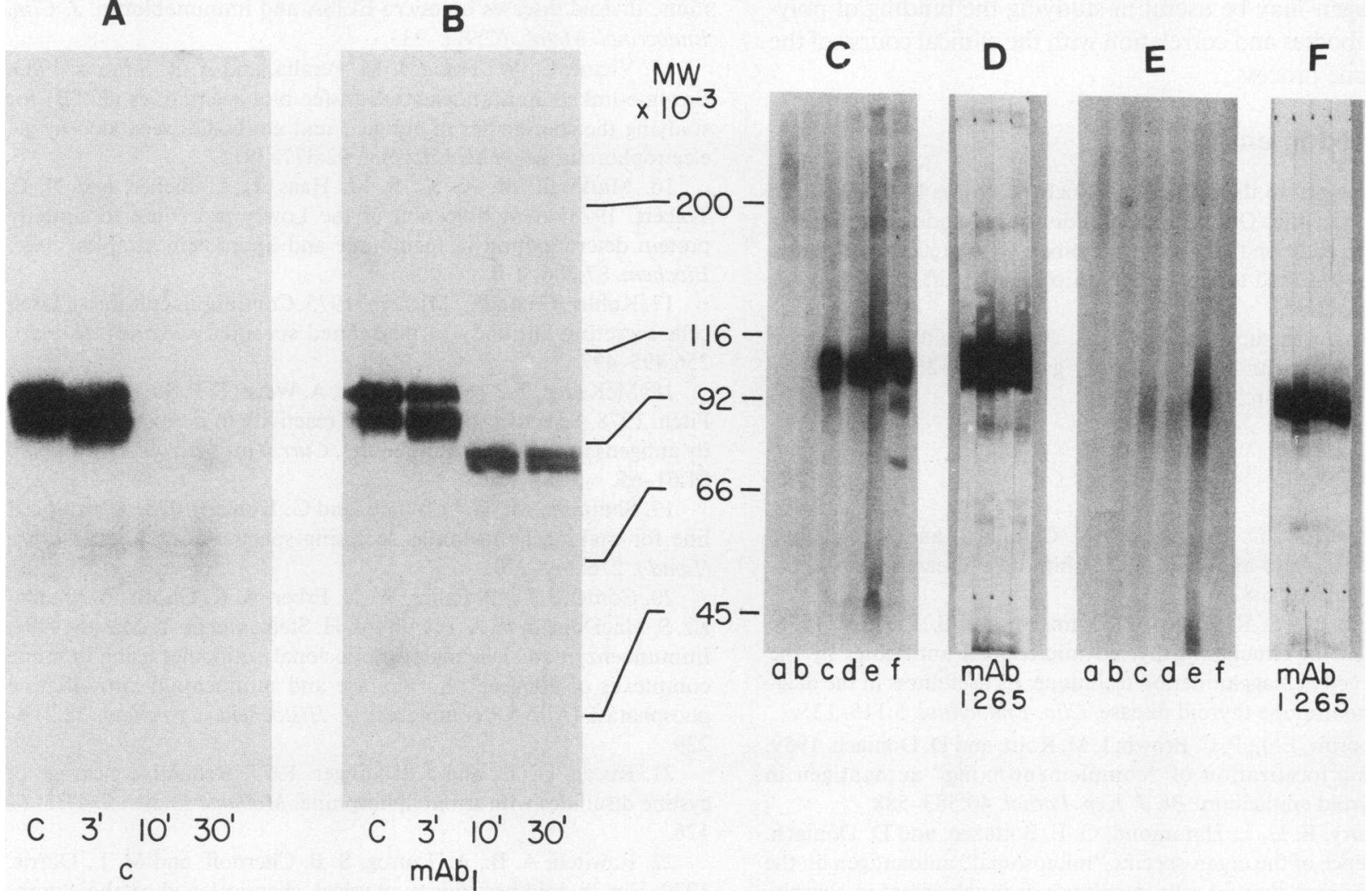

Figure 7. Effect of trypsin on immunoreactivity of the microsomal antigen. $A$ and $B$ represent the result of trypsin digestion of microsomal antigen for 0-30 min. $500 \mu \mathrm{g}$ of solubilized microsomal proteins was incubated with $5 \mu \mathrm{g}$ of trypsin in a waterbath at $37^{\circ} \mathrm{C}$ for 3 , 10 , and $30 \mathrm{~min}$. Thereafter, a fivefold excess (wt/wt) of trypsin inhibitor was added. In control lane $(C)$, trypsin was preceded by the addition of inhibitor and incubation was for $30 \mathrm{~min}$ in the same conditions. The proteins were then electrophoresed in PAGE, and Western

somal antigenicity by immunofluorescence has been described in thyroid cancer using patient's serum (26). Further evaluation will be of interest; it will use MAb with a high affinity and specificity for the antigen. Finally, such results explain the decrease of microsomal antigenicity and peroxidase activity which has been reported in these tumors (26).

Previous enzymatic and immunological studies have shown that microsomal antigenicity and peroxidase activity were closely related. However, an identity between these two activities has been difficult to prove. Roitt described in 1964 (27) that trypsinization of the microsomal antigen led to a $75 \%$ decrease of antigenicity. Mariotti et al. (28) described a loss of microsomal antigenicity after such treatment, using an iodinated IgG. As one patient's serum was used, the data of that study have to be considered cautiously. In contrast, trypsinization of peroxidase is a useful step in preparation of TPO (29). Our study shows that trypsinization leads to a considerable decrease of antigenicity of the molecule and formation of specific unique $84-$ and $88-\mathrm{kD}$ bands. Interestingly, the molecular weight of our trypsinized microsomal antigen is the same as reported recently by Cooper et al. for trypsinized porcine TPO (30). Presumably this modification of structure is useful in purification of TPO and does not cause loss of enzymatic activity. Results of digestion of the $107-\mathrm{kD}$ band by V8 pro-

blotted using either control serum $(c)$ or $M A_{1}$. $(A)$ Patient's serum $(c)$ was used at 1:200 dilution and bound antibodies were visualized with ${ }^{125}$ I protein A. (B) MAb was used at 1:1,500 dilution and visualized by peroxidase-labeled antibody. $C-F$ display the immunoreactivity of microsomal antigen before $(C$ and $D)$ and after $(E$ and $F)$ incubation with trypsin ( $4 \mu \mathrm{g} / 400 \mathrm{mg}$ protein) and PAGE, and after Western blotting using control serum (lane $a$ ), five high MCHA titer serum (lanes $b-f$ ), and four MAbs (lanes 1, 2, 5, and 6).

tease indicate that the two immunoreactive bands are not identical. The 101-kD band appears not to be a degradative product of the $107-\mathrm{kD}$ band, and is resistant to $\mathrm{V} 8$ protease. These treatments also indicate that the antigenic regions recognized by the MAb are different from the epitopes recognized by human polyclonal antibodies, and explain the failure of polyclonal sera to inhibit the binding of MAb to the microsomal antigen on ELISA plates or to the 101-107-kD bands in Western blots (data not shown). We can hypothesize that the 101- and 107-kD bands share common epitopes, which is proven by binding of human polyclonal and MAb, and are equally sensitive to trypsin, but that the $107-\mathrm{kD}$ band contains a protease-sensitive domain. It is possible that the two forms of this protein are developed from one gene by utilizing differential splicing of exons, or that posttranslational processing causes the two forms to occur. cDNAs for porcine TPO (31) and human TPO (32) have been cloned and their sequences published. Kimura et al. (32) have noted the presence of two mRNAs formed by alternate splicing, which presumably explains the 107- and 101-kD proteins we have reported.

A difference in the expression of microsomal antigen (TPO) has been identified among thyroid carcinomas and may suggest that the mechanisms promoting carcinogenesis may be different among those tumors. Finally, proteolytic treatment 
of the antigen may be useful in studying the binding of polyclonal antibodies and correlation with the clinical course of the autoimmune process.

\section{Acknowledgments}

The authors want to thank Birgitta Clinchy, Douglas Darling, Kazuo Ichikawa, and Gilles Otten for helpful discussion and technical assistance, and in addition thank Myrna Zimberg for secretarial assistance. We are very indebted to Dr. Alvin Taurog for the gift of purified hog thyroid peroxidase.

This work was supported by U. S. Public Health Service grant AM13377, American Cancer Society grant PDT-260, and by the David Wiener Research Fund.

\section{References}

1. Roitt, I. M., D. Doniach, P. N. Campbell, and R. Vaughan Hudson. 1956. Auto-antibodies in Hashimoto's disease (lymphadenoid goitre). Lancet. ii:820-821.

2. Amino, N., S. R. Hagen, N. Yamada, and S. Refetoff. 1976. Measurement of circulating thyroid microsomal antibodies by the tanned red cell hemagglutination technique: its usefulness in the diagnosis of autoimmune thyroid disease. Clin. Endocrinol. 5:115-125.

3. Holborow, E. J., P. C. Brown, I. M. Roitt, and D. Doniach. 1959. Cytoplasmic localization of "complement-fixing" autoantigen in human thyroid epithelium. Br. J. Exp. Pathol. 40:583-588.

4. Khoury, E. L., L. Hammond, G. F. Bottazzo, and D. Doniach. 1981. Presence of the organ-specific "microsomal" autoantigen on the surface of human thyroid cells in culture: its involvement in complement-mediated cytotoxicity. Clin. Exp. Immunol. 45:316-328.

5. Chiovato, L., P. Vitti, A. Lombardi, L. D. Kohn, and A. Pinchera. 1985. Expression of the microsomal antigen on the surface of continuous rat thyroid cells is modulated by thyrotropin. J. Clin. Endocrinol. Metab. 61:12-16.

6. Banga, J. P., G. Pryce, L. Hammond, and I. M. Roitt. 1985. Structural features of the autoantigens involved in thyroid autoimmune disease: the thyroid microsomal/microvillar antigen. $\mathrm{Mol}$. Immunol. 22:629-642.

7. Hamada, N., C. Grimm, H. Mori, and L. J. DeGroot. 1985. Identification of a thyroid microsomal antigen by Western blot and immunoprecipitation. J. Clin. Endocrinol. Metab. 61:120-128.

8. Hamada, N., L. Portmann, and L. J. DeGroot. 1987. Characterization and isolation of thyroid microsomal antigen. $J$. Clin. Invest. 79:819-825.

9. Kajita, Y., D. Morgan, A. B. Parkes, and B. Rees Smith. 1985. Labeling and immunoprecipitation of thyroid microsomal antigen. FEBS (Fed. Eur. Biochem. Soc.) Lett. 187:334-338.

10. Portmann, L., N. Hamada, G. Heinrich, and L. J. DeGroot. 1985. Antithyroid peroxidase antibody in patients with autoimmune thyroid disease: possible identity with anti-microsomal antibody. $J$. Clin. Endocrinol. Metab. 61:1001-1003.

11. Czarnocka, B., J. Ruf, M. Ferrand, P. Carayon, and S. Lissitzky. 1985. Purification of the human thyroid peroxidase and its identification as the microsomal antigen involved in autoimmune thyroid diseases. FEBS (Fed. Eur. Biochem. Soc.) Lett. 190:147-152.

12. Weetman, A. P., C. A. Gunn, D. P. Rennie, R. Hall, and A. M. McGregor. 1985. The production and characterization of monoclonal antibodies to the human thyroid microsome. J. Endocrinol. 105:4752.

13. Banga, J. P., R. Mirakian, L. Hammond, G. Pryce, S. Bidey, G. F. Botazzo, W. P. Weetman, A. M. McGregor, and I. M. Roitt. 1986. Characterization of monoclonal antibodies directed towards the microsomal/microvillar thyroid autoantigen recognized by Hashimoto autoantibodies. Clin. Exp. Immunol. 64:544-554.

14. Kotani, T., K. Umeki, S. Matsunaga, E. Kato, and S. Ohtaki. 1986. Detection of autoantibodies to thyroid peroxidase in autoim- mune thyroid diseases by micro-ELISA and immunoblottin. J. Clin. Endocrinol. Metab. 62:928-933.

15. Victor, C., W. Tsang, J. M. Peralta, and A. R. Simons. 1983. Enzyme-linked immunoelectrotransfer blot techniques (EITB) for studying the specificities of antigens and antibodies separated by gel electrophoresis. Methods Enzymol. 92:377-391.

16. Markwell, M. A. K., S. M. Haas, L. L. Bieber, and N. E. Tolbert. 1978. A modification of the Lowry procedure to simplify protein determination in membrane and lipoprotein samples. Anal. Biochem. 87:206-210.

17. Kohler, G., and C. Milstein. 1975. Continuous cultures of fused cells secreting antibody of predefined specificity. Nature (Lond.). 256:495-497.

18. McKearn, T. J., M. Sarmiento, A. Weiss, F. P. Stuart, and F. W. Fitch. 1978. Selective suppression of reactivity to rat histocompatibility antigens by hybridoma antibodies. Curr. Top. Microbiol. Immunol. 81:61-65.

19. Shulman, M., C. D. Wilde, and G. Kohler. 1978. A better cell line for making hybridomas secreting specific antibodies. Nature (Lond.). 276:269-270.

20. Cordel, J. L., B. Falini, W. N. Erber, A. K. Ghosh, Z. Abdulaziz, S. MacDonald, K. A. F. Pulford, H. Stein, and D. Y. Mason. 1984. Immunoenzymatic labeling of monoclonal antibodies using immune complexes of alkaline phosphatase and monoclonal anti-alkaline phosphatase (APAAP complexes). J. Histochem. Cytochem. 32:219229.

21. Ruegg, U. T., and J. Rudinger. 1977. Reductive cleavage of cystine disulfides with tributylphosphine. Methods Enzymol. 47:111126.

22. Rawitch, A. B., A. Taurog, S. B. Chernoff, and M. L. Dorris. 1979. Hog thyroid peroxidase: physical, chemical, and catalytic properties of the highly purified enzyme. Arch. Biochem. Biophys. 194:244-257.

23. Satoh, J., B. S. Prabhaker, M. V. Haspel, F. Ginsberg-Fellner, and A. L. Notkins. 1983. Human monoclonal autoantibodies that react with multiple endocrine organs. N. Engl. J. Med. 309:217-220.

24. Khoury, E. L., G. F. Botazzo, and I. M. Roitt. 1984. The thyroid "microsomal" antibody revisited. Its paradoxical binding in vivo to the apical surface of the follicular epithelium. J. Exp. Med. 159:577-591.

25. Colletta, G., A. Fusco, A. M. Cirafici, F. Ciliberto, M. Santoro, and G. Vecchio. 1985. Thyroid cell transformation: the role of Ras oncogene in vivo and in vitro. In Thyroid Cancer. C. Jaffiol and G. Milhaud, editors. Elsevier/North Holland, Amsterdam. 39-45.

26. Goudie, R. B., and H. M. McCallum. 1963. Loss of tissue-specific autoantigen in thyroid tumors. A demonstration by immunofluorescence. Lancet. ii:1035-1038.

27. Roitt, I. M., N. R. Ling, D. Doniach, and K. G. Couchman. 1964. The cytoplasmic auto-antigen of the human thyroid. I. Immunological and biochemical characteristics. Immunology. 7:375-393.

28. Mariotti, S., A. Pinchera, C. Marcocci, P. Vitti, C. Urbano, L. Chiovato, M. Tosi, and L. Baschieri. 1979. Solubilization of human thyroid microsomal antigen. J. Clin. Endocrinol. Metab. 48:207-212.

29. DeGroot, L. J., and A. M. Davis. 1962. Studies of the biosynthesis of iodotyrosines: a soluble thyroidal iodide-peroxidase tyrosineiodinase system. Endocrinology. 70:492-504.

30. Cooper, D. S., F. Maloof, and E. C. Ridgway. 1984. Rat thyroid peroxidase biosynthesis in vitro: studies using antisera to porcine thyroid peroxidase. Annual Meeting of the American Thyroid Association, New York (Abstract No. 26).

31. Magnusson, R. P., J. Gestautas, P. Seto, A. Taurog, and B. Rapoport. 1986. Isolation and characterization of a cDNA clone for porcine thyroid peroxidase. FEBS Letters. 208:391-396.

32. Kimura, S., T. Kotani, O. W. McBride, K. Umeki, K. Hirai, T. Nakayama, and S. Ohtaki. 1987. Human thyroid peroxidase: complete cDNA and protein sequence, chromosome mapping, and identification of two alternately spliced mRNAs. Proc. Natl. Acad. Sci. USA. 84:5555-5559. 